\title{
Benign Skull Base Neoplasm
}

National Cancer Institute

\section{Source}

National Cancer Institute. Benign Skull Base Neoplasm. NCI Thesaurus. Code C155793.

A non-metastasizing neoplasm that arises from the skull base. 